\title{
Relações Públicas: o futuro da atividade é o futuro da profissão?
}

Public Relations: is the future of the activity the future of the profession?

Relaciones públicas: iel futuro de la actividad es el futuro de la profesión?

Márcio Simeone Henriques

- Doutor em Comunicação Social pela Universidade Federal de Minas Gerais (UFMG)

- Mestre em Educação pela Universidade Federal do Rio de Janeiro (UFRJ)

- Bacharel em Relações Públicas pela Universidade Federal de Minas Gerais (UFMG)

- Professor do Departamento de Comunicação Social da UFMG

- Organizador e coautor do livro Comunicação e estratégias de mobilização social

- simeone@fafich.ufmg.br 
As atividades de Relações Públicas têm ampliado significativamente, nos últimos anos, o seu escopo e a sua inserção nas mais diversas instituições. No entanto, os dilemas vividos pelos profissionais com frequência apontam o fracasso na constituição dessas atividades como uma profissão ou, pelo menos, a necessidade de reformar os seus estatutos. As principais questões que cercam esses dilemas exigem visão mais ampla e mais profunda, tomando por base os pilares sobre os quais o estatuto deontológico e disciplinar da profissão foi proposto.

PALAVRAS-CHAVE: RELAÇÕES PÚBLICAS • PROFISSÃO • DEONTOLOGIA

\section{Abstract}

Public Relations activities have been broadening significantly in recent years and have been extended to more institutions. However, the dilemmas experienced frequently by the professionals indicate the failure of constitution of such activities as a profession or, at least, the need to restate the applicable rules. The main questions that involve these dilemmas demand broader and deeper vision, taking into account the pillars on which deontological statutes and professional discipline of Public Relations were proposed.

KEYWORDS: PUBLIC RELATIONS • PROFESSION • DEONTOLOGY

Resumen

Las actividades de Relaciones Públicas han ampliado significativamente en los últimos años su alcance y su inserción a las más diversas instituciones. Sin embargo, los dilemas vividos por los profesionales indican con frecuencia el fracaso en la constitución de estas actividades como una profesión o, por lo menos, la necesidad de reformar sus estatutos. Las principales preguntas planteadas acerca de estos dilemas exigen una visión más amplia y más profunda, que tenga en cuenta los pilares sobre los cuales se propusieron los estatutos deontológico y disciplinar de la profesión.

PALABRAS CLAVE: RELACIONES PÚBLICAS • PROFESIÓN • DEONTOLOGÍA 
0 s dilemas vividos pelos profissionais de relações públicas e as contradições que cercam a atividade, não só no Brasil como em todos os países nos quais logrou especializar-se e atingir o status de profissão, têm sido explicados ora pela profissionalização relativamente recente, ora pela incompetência dos próprios praticantes em posicionar a profissão, constituindo com precisão seus fundamentos. Afora os questionamentos que são dirigidos ao conjunto das profissões contemporâneas - debate que põe em xeque os modelos de exercício profissional vigentes -, é necessário investigar em maior detalhe e com visão mais abrangente a situação atual das Relações Públicas e as razões desses dilemas e dessas contradições. Podemos levantar pontos importantes para guiar nosso raciocínio na direção dessa visão mais apurada, para compreendermos o futuro da atividade e da profissão.

Uma explicação das atividades de Relações Públicas como sendo todas aquelas capazes de gerar e manter um relacionamento no espaço público entre as organizações e os grupos a que estão de alguma forma ligadas exige uma compreensão mais refinada sobre o que realmente fundamenta a atividade: a permanente tensão entre interesses privados e públicos. Sob essa perspectiva, entram em jogo a aprovação e a legitimação que os grupos podem ou não conferir a uma organização. Problematizando tal relação em termos coletivos, em discussões acessíveis e publicamente difundidas, esses grupos se tornam públicos, definidos basicamente pela sua inserção em controvérsias (mesmo que potenciais) quanto à natureza dos problemas que se colocam à atenção da coletividade (se privados ou públicos).

Posicionar-se publicamente é uma necessidade imperiosa e permanente para qualquer organização e podemos pensar que o desenvolvimento desse processo ocorre independente de um setor ou departamento específico para essa finalidade. Entretanto, as Relações Públicas inserem-se em um contexto moderno de divisão e especialização do trabalho e materializaram-se como um campo de práticas definidas, já que administrar processos complexos de relacionamento passou a ser entendido como tarefa especializada. Prova disso é sua inserção no organograma de diversas organizações ou a contratação de serviços de assessoria e consultoria.

A profissionalização decorre não só do desenvolvimento da base de expertise da atividade, mas também da necessidade de controle social sobre um conjunto de funções bem definidas e com certas restrições sobre quem pode exercê-las. Para isso têm de concorrer duas condições: a existência de uma disciplina e a existência de um estatuto deontológico. A primeira diz respeito à ordenação de um corpo teórico e prático que a torne socialmente reconhecível - que possua praticantes ou "discípulos" e seja passível de ser ministrado a novos praticantes. A segunda diz respeito às formas de exercício que são socialmente aceitáveis, materializadas em um conjunto de regras e princípios de conduta. Aqui se apresenta um problema que carece ser enfrentado com vigor por praticantes e pesquisadores da área: por que a evolução da atividade demonstra 
um crescimento extraordinário da prática e dos conhecimentos de atividades de Relações Públicas, enquanto se detecta um fenômeno de declínio de reconhecimento da profissão - ao menos nos termos em que foi historicamente definida - em várias partes do mundo?

\section{A construção de um problema}

Podemos suspeitar, a princípio, que tanto a disciplina quanto o estatuto deontológico da profissão não tenham se estabelecido e consolidado com força suficiente. Ao contrário, porém, o exame histórico nos apresenta um portentoso esforço nesse sentido, especialmente no período após a Segunda Guerra Mundial, de onde provém boa parte das formulações teóricas e das iniciativas mais importantes dos próprios praticantes de criar as bases disciplinares e deontológicas. Pelo menos até a década de 1960 era notória uma expansão das Relações Públicas como profissão, época em que os praticantes se organizaram mais efetivamente como categoria e que também é profícua no sentido das formulações teóricas. Essa construção evoluiu pari passu com a articulação dos praticantes. Fica evidente a preocupação de definir as técnicas e os processos de Relações Públicas e também de distinguir essas práticas da Propaganda - sob o impacto do uso intensivo das técnicas de propaganda na primeira metade do século XX. É representativa a articulação internacional que culminou com a fundação da International Public Relations Association (IPRA) em 1955, desde o início preocupada em formular um código de ética internacional para a profissão, o que se alcançou com a aprovação, em 1965, do chamado Código de Atenas. Uma das considerações a justificar sua promulgação era a de que "a utilização das técnicas que permitem entrar simultaneamente em contato com milhões de pessoas, dá aos profissionais de relações públicas um poder que importa limitar pelo respeito da ética e dos valores da profissão" (CÓDIGO, 1965) ${ }^{1}$.

Da demanda por controle social advêm as diversas regulamentações em vários países - seja de modo de exercício exclusivo ou não, sob a forma de le is próprias, ou de normatização legal difusa. Houve, com efeito, tentativa importante de gerar as condições necessárias de instituição e de controle social da profissão, que contrasta, mais recentemente, com um reiterado discurso de "fracasso". Este se materializa nas afirmativas constantes que apontam a falta de um objeto específico, a dificuldade de definir e explicar o que é a profissão e o que faz o profissional e, no caso brasileiro, o anacronismo da regulamentação do seu exercício.

10 Código de Ética Internacional dos Profissionais de Relações Públicas, conhecido como Código de Atenas, foi adotado pela conferência da International Public Relations Association (Ipra) que se realizou em Atenas em 12 de maio de 1965, tendo sido alterado em Teerã em 17 de abril de 1968. 0 código de ética profissional brasileiro foi promulgado pelo Conselho Federal de Profissionais de Relações Públicas (Conferp) em 1972. 


\section{Formulando hipóteses}

Os sintomas do descompasso e dos paradoxos entre a atividade e a profissão de Relações Públicas são por demais evidentes. É recomendável verificar com cuidado de que modo evoluiu a atividade e quais as possíveis incongruências com os postulados normativos que constituíram a profissão. Podemos apontar pelo menos duas pistas, lançadas aqui apenas como hipóteses, não mutuamente excludentes:

1) Ampliação rápida do escopo da atividade - O exame do histórico da atividade pode demonstrar que esta ampliou extraordinariamente suas funções ao longo do tempo, o que tem a ver com pelo menos dois fenômenos importantes: a extrapolação do entendimento da atividade de Relações Públicas como sendo do âmbito da comunicação de massa (com a progressiva inserção do conceito de comunicação dirigida); e a visão da complexidade organizacional e de suas relações comunicativas (que conduz ao conceito de comunicação integrada). Com isso, as próprias práticas não se deixam limitar às atividades de publicity ou ao uso de técnicas de propaganda e não mais se conformam apenas às funções institucionais. As mudanças sociais e organizacionais desde a década de 1970 forçaram adaptação rápida a novos cenários, mais mutáveis. Mas transformações no campo das práticas e das reflexões teóricas não se fizeram acompanhar na mesma medida e na mesma velocidade da formulação de doutrinas e de alterações nos estatutos profissionais. Isso talvez se explique pelo timing distinto das práticas cotidianas, da produção e da reprodução do conhecimento e das regulamentações da área.

2) Insuficiência, inconsistência e incongruência das doutrinas profissionais - Cabe observar em que medida as doutrinas ${ }^{2}$ baseadas no modelo de conduta até então proposto como padrão normativo (e legal) para a profissão têm sido historicamente seguidas. Esse modelo, fundado na distinção entre atividades de Propaganda e de Relações Públicas, pode não ter logrado êxito completamente, como evidenciam muitas das persistentes visões críticas aplicadas às relações públicas ("fabricantes de consensos", "manipuladores de mitos" etc.). A indefinição dos liames entre Relações Públicas e Propaganda traz em decorrência a desconfiança dos públicos, que tendem a ver na atividade de Relações Públicas uma função de persuasão e manipulação, transposta aos praticantes. Assim, perde força e efeito um dos pilares centrais do controle social. Na raiz da questão encontram-se concepções concorrentes acerca da finalidade e do modus operandi do profissional de relações públicas, como ocorre entre as que derivam do chamado modelo de informação pública e as que tiveram a forte influência da atuação e das reflexões de Edward Bernays. Ao classificarem os modelos de Relações Públicas historicamente constituídos, Grunig e Hunt (1984) acabam propondo como síntese evolutiva um mo-

2 Entendemos aqui por doutrina tanto o conjunto de princípios basilares do sistema profissional, quanto as interpretações dos princípios normativos desse sistema. 
delo que carrega um ethos implícito na ideia da excelência, baseada em relações simétricas e bidirecionais.

Tais considerações não nos autorizam a afirmar, como muitos, que a profissão carece de doutrina(s). Queremos sustentar que, pelo exame dos elementos normativos mais significativos (em termos brasileiros e internacionais), gerouse (e mantém-se) um corpo doutrinário que é, na atualidade, a um só tempo, insuficiente - em relação à ampliação do escopo da atividade; inconsistente por não dar conta de sustentar uma delimitação mais precisa entre as atividades de Relações Públicas e de Propaganda; e incongruente - com a prática que atualmente é demandada e o tipo de profissionalização para isso exigido.

\section{As dúvidas quanto ao futuro}

Essas hipóteses podem, talvez, guiar discussões mais férteis sobre as relações entre a atividade e a profissão de Relações Públicas. Tais relações não são de perfeita correspondência - como, ademais, não são para qualquer outro campo profissional. É necessário perceber os pontos de congruência que produzem o sentido de "profissão" para as Relações Públicas, para examinar em que medida se sustenta sob a forma atual. A valorização crescente e uma farta produção de conhecimentos lançam novos elementos para um dever-ser do exercício das Relações Públicas, colocando-nos diante de oportunidades e de riscos. Oportunidades de pensar e construir de modo mais criativo as práticas dos relacionamentos públicos - em um mundo sob o impacto de grandes transformações, e riscos que não se encontram, necessariamente, na perda de um campo específico de atuação profissional, mas na perda de controle social sobre essas práticas. Não se trata de um problema confinado a uma categoria profissional, mas que diz respeito a toda a sociedade, em termos de como a área organiza as relações comunicativas no espaço público, dispondo os seus meios e instrumentos e regulando os seus processos.

Quanto ao discurso que propala o fracasso da profissão, é preciso cautela e o reconhecimento de que, dentro do modelo no qual se constituiu, persiste a crença em certos princípios que fundamentam as ações de muitos praticantes e que ainda se inscreve com força na formação acadêmica dos noviços. Não se pode confundir a forma como se dá a regulamentação no Brasil - a esta altura já reconhecida como insustentável - com a ideia de que toda a prática profissional seja anacrônica e tenha perdido o seu significado. Como vemos hoje, o futuro da profissão de Relações Públicas é incerto. Depende de como interpretaremos o futuro da atividade, de como a sociedade irá reconhecê-la, de como se reposicionarão a sua especialidade e, consequentemente, seus estatutos.

\section{Referências}

CóDIGO de Atenas. Disponível em: <http://www.abrpnacional.com.br/files/atenas.pdf>. Acessado em: 09 abr. 2009. GRUNIG, James; HUNT, Todd. Managing public relations.new York: Holt, Rinehart and Winston, 1984. 